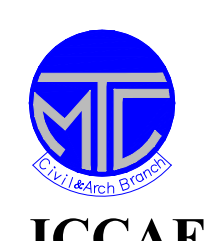

Military Technical College

Kobry Elkobbah,

Cairo, Egypt

\author{
7 th International Conference \\ On Civil \& Architecture \\ Engineering
}

\title{
BEHAVIOR OF TUNNEL WITH CONCRETE LINING SUBJECTED TO UNDERGROUND EXPLOSION IN ROCK MEDIA
}

\begin{abstract}
ISMAIL MOHAMED KAMAL*

In this study, a circular cross-section tunnel with concrete lining is analyzed by the finite element code AUTODYN 3-D version 4.3., which is probably the most extensive code dealing with explosive loads in the world.

First, a model calibration was performed for the AUTODYN finite element parameters and material models by using a field test problem with available field measurements. Then, based on the calibration results, a parametric study has been performed by means of finite element non-linear dynamic analysis to investigate the effect of underground explosion on the behaviour of circular tunnel with concrete lining in rock media. A charge of $2500 \mathrm{~kg}$ TNT was used as an explosive load. This charge was located at $3.25 \mathrm{~m}$-bellow ground surface with two crown-detonation distances 10 and $15 \mathrm{~m}$ for all models.

Finally, a non-linear rational analysis is conducted for the parametric study results to develop simple equations to determine peak displacements and strains for circular tunnels with concrete lining. These equations may help tunnel designers and military engineers in estimating displacements, and strains, then overall damage in the tunnels with no need to deal with complex finite element non-linear dynamic codes.
\end{abstract}

\section{KEY WORDS}

Finite Element, Underground Explosion, Circular Tunnel, Rock Media, Concrete Lining.

\footnotetext{
* Permanent staff $(\mathrm{PhD})-$ Civil Eng. Department, Military Technical Collage - Cairo, EGYPT
} 


\section{INTRODUCTION}

Due to the progressive development of military destructive weapons such as conventional weapons, a consequence development of the fortified structures is essential. One of the most important types of fortified structures is a tunnel in rock media. The basic premise of this work is studying the response of circular tunnels with concrete lining in rock-media exposed to high explosion loads. This damage might occur due to wave propagation generated by those explosion loads.

\section{MODEL CALIBRATION}

In order to calibrate AUTODYN [1] finite element model results, the finite element package is used to create a three dimensional finite element model for a field test problem with available measurements. The selected test was a field-blasting test carried out at the granite site [8]. The field layout, as shown in figure (1), consists of a step charge hole with a total depth of $11 \mathrm{~m}$. The upper $6 \mathrm{~m}$ of the charge hole has a diameter of $1.5 \mathrm{~m}$ and the bottom $5 \mathrm{~m}$ has a diameter of $0.8 \mathrm{~m}$. The measuring point was placed at $25 \mathrm{~m}$ distance from the charge hole center. The test is carried out with an equivalent TNT charge weight $50 \mathrm{~kg}$ where loading densities $20 \mathrm{~kg} / \mathrm{m}^{3}$. Finite element model is created using the same techniques and RHT brittle material constitutive model that have been used in the parametric study. finite element models as shown in figure (2). A comparison between the finite element model and the field-measured data for acceleration-time history at the same target point is presented in figure (3). The results of the finite element model have a good agreement with the field-measured data in terms of amplitudes and frequencies.

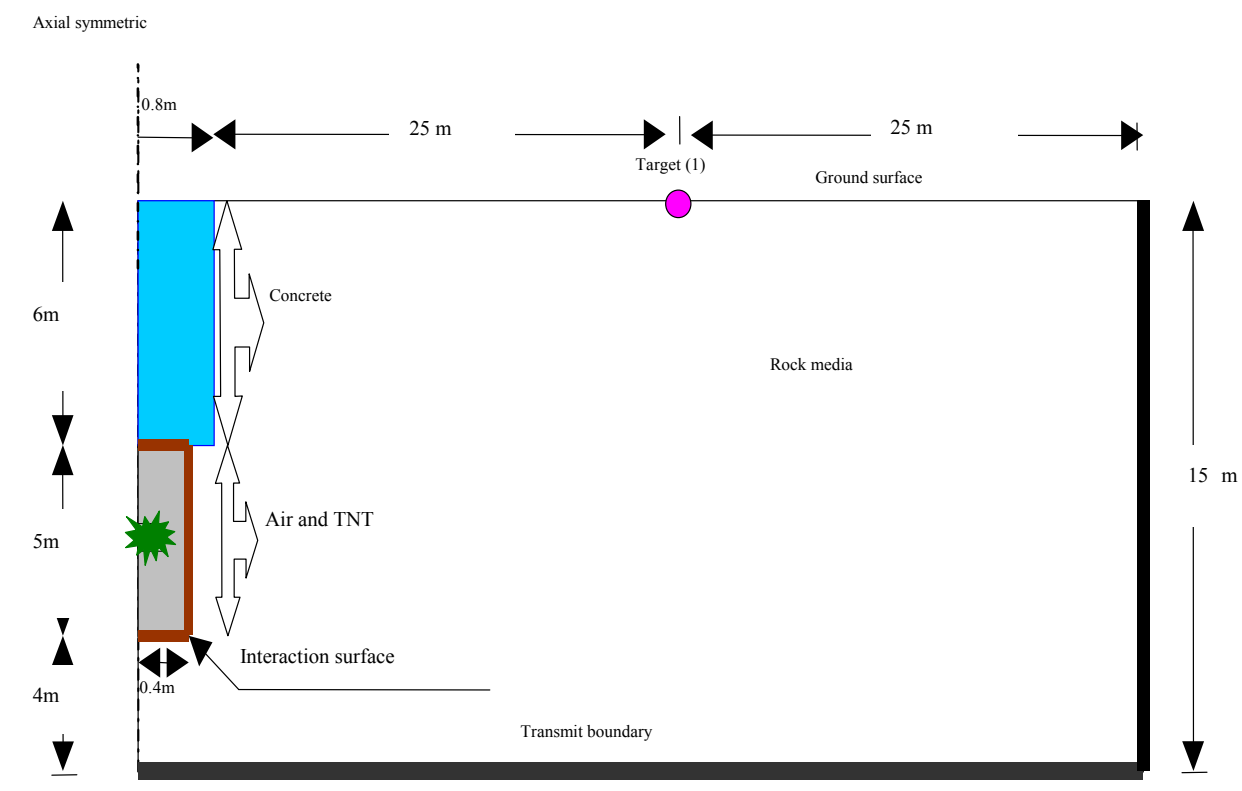

Fig. 1 Layout of The Field Test Problem 


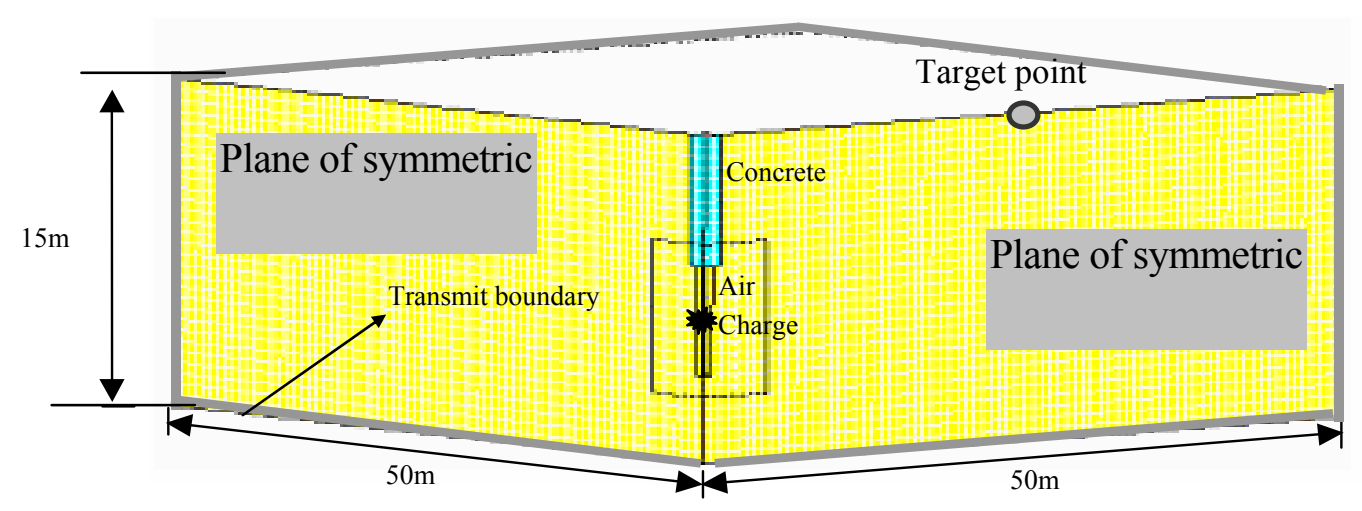

Fig. 2 Three-dimensional AUTODYN finite element model of the field test problem

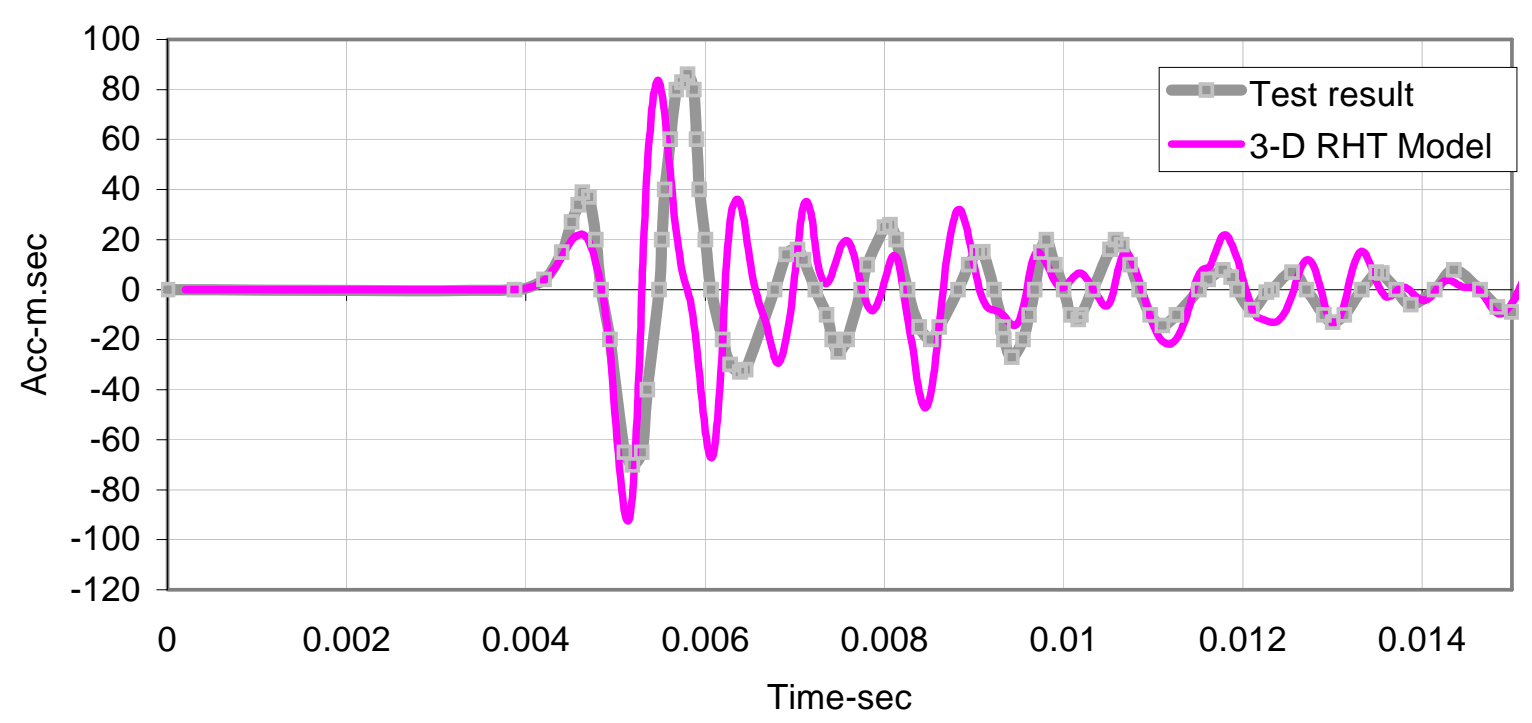

Fig. 3 Field-Measured Data Versus FE Model Response for Acceleration Time History at Target Point Location.

\section{Model Description}

With regard to finite element solution, an appropriate mesh is employed to represent the geometry of the problem. Due to the symmetric conditions of this problem and to minimize the running time of the model, only a quarter of the domain is taken as a computation model. Figure (4) shows the finite element mesh for which the model dimensions in the $X$ and $Y$-axes are $5 R$ and $7.5 \mathrm{~m}$ respectively. The non-reflection boundary is given by transmitting the boundary conditions at ambient rock masses, the plane $X=0$ and $Y=0$ are treated as symmetric boundary as presented in figure (4). The rock and lining are simulated by solid elements in a three-dimensional finite formulation. A charge of $2500 \mathrm{~kg}$ TNT was used as an explosive load. This charge was located at $3.25 \mathrm{~m}$ bellow ground surface with two crown-detonation distances $10 \mathrm{~m}$ and $15 \mathrm{~m}$ for all models. Three radii are adopted in this study $3 \mathrm{~m}, 4.5 \mathrm{~m}$, and $6 \mathrm{~m}$. 
Joint to joint are used to simulate rock-lining interaction. The concrete lining thickness to arc radius (tc/R) ratio was considered (1/30), (1/15), (1/10), and (1/5) as shown in figure (5). Transmitting boundary is applied at the model boundaries to represent the infinite media around the tunnel.

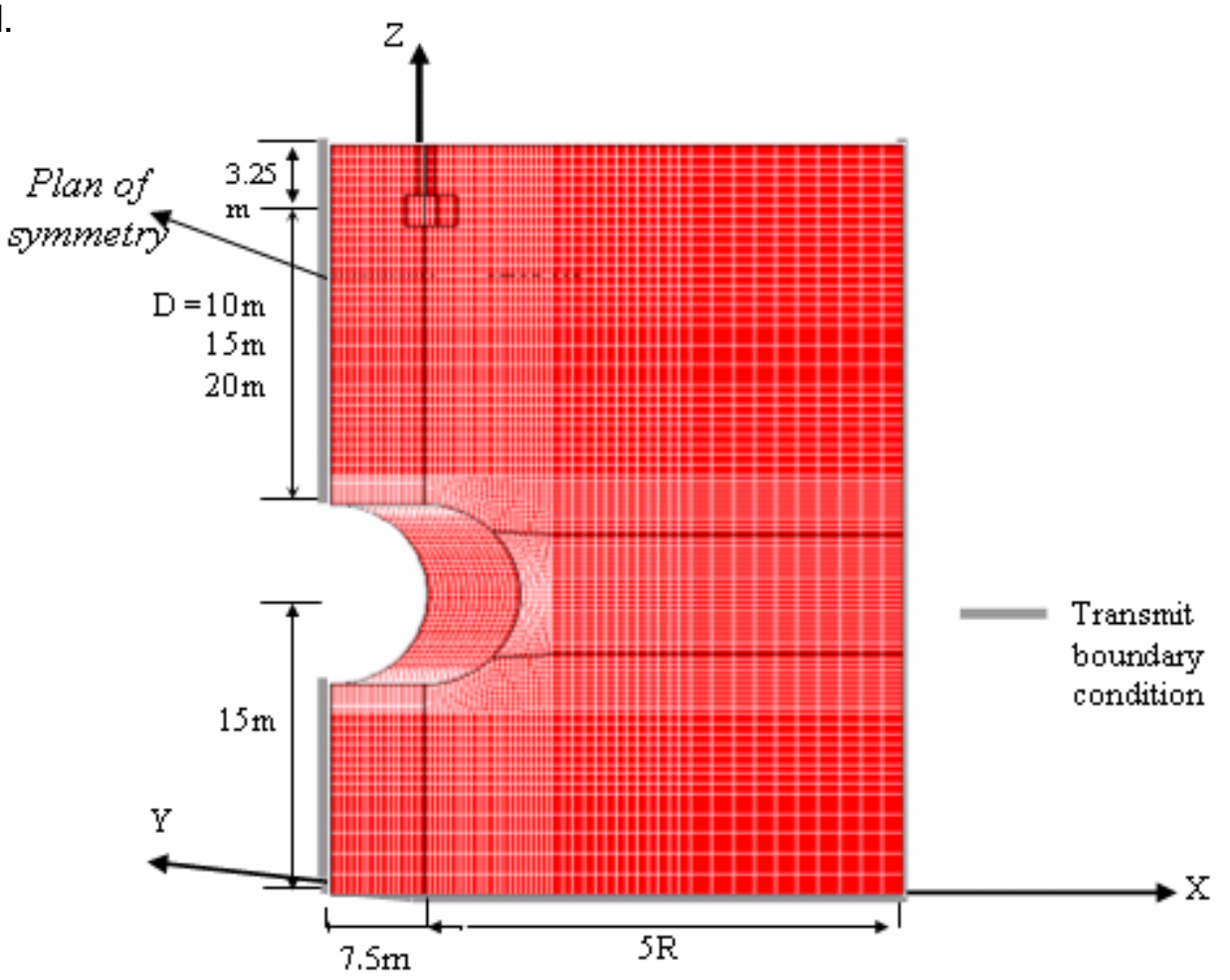

Fig. 4 ATOUDYN Three Dimensional Finite Element Mesh Circular Section Tunnel.

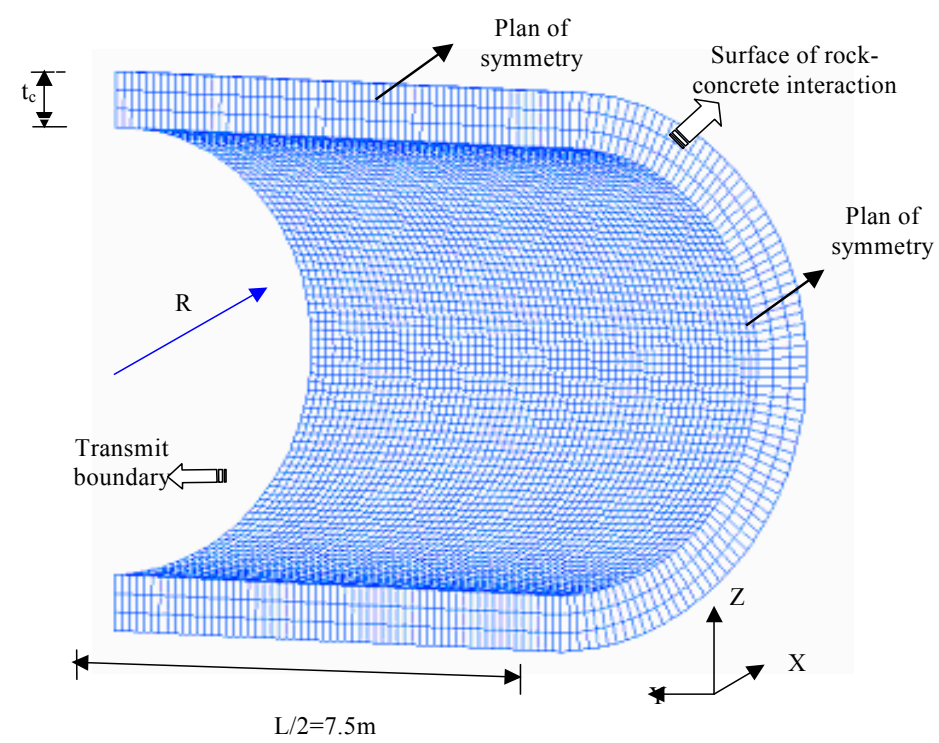

Fig. 5 Three Dimensional Finite Element Model of Concrete Lining Tunnel 


\section{Material Properties}

\section{Rock}

The rock is assumed to be continuous, isotropic and homogeneous. RHT [6] brittle material model is used for characterizing the nonlinear behavior of the rock in this study. Material properties for poor rock, adopted in these models are shown in table (1).

Table 1 Rock properties

\begin{tabular}{|c|c|c|c|c|c|c|c|c|}
\hline Rock & Rock & & Modulus & & Bulk & Shear & Unc. & \\
Quality & Mass & Density & of & Poisson & Modulus & Modulus & Com. & Failure \\
Design & Ratting & $\gamma$ & Elasticity & ratio & K & G & Strength & Strain \\
(RQD) & RMR) & $\mathrm{t} / \mathrm{m}^{3}$ & $\mathrm{E}$ & $v$ & $\mathrm{GPa}$ & $\mathrm{GPa}$ & $\mathrm{MPa}$ & \\
$\%$ & $\%$ & & $\mathrm{GPa}$ & & & & & \\
\hline \hline $25-50$ & 44 & 2.21 & 8.5 & 0.3 & 7.083 & 3.27 & 10 & 0.0075 \\
\hline
\end{tabular}

The values of strength and moduli were selected based on available data in numerous references [3],[7].

\section{Concrete}

Non-linear RHT material model is used in this analysis with concrete properties as follows: Compressive strength $=35 \mathrm{MPa}$, Failure strain $=0.03$, shear modulus $=16700 \mathrm{MPa}$, and Tensile strength $=3.5 \mathrm{MPa}$

\section{TNT}

The numerical modeling of equivalent explosive TNT is simulated by 200 elements Euler processor mesh and are assumed to satisfy the equation of state the "Jones - Wilkins - Lee" (JWL) [6], standard constants used for TNT are:

Reference density $\mathrm{g} / \mathrm{cm}^{3}=1.63$, C-J Detonation Velocity $=6.4 \times 10^{3}$,

C-J energy / unit volume $=6 \times 106$, and C-J Pressure $=2.1 \times 107 \mathrm{kPa}$

\section{Air}

The numerical modeling of air is simulated by 200 elements Euler processor mesh and are assumed to satisfy the equation of state of ideal gas (EQS), standard constants used of air are:

Reference density $=1.225 \times 10^{-3} \mathrm{~g} / \mathrm{cm}^{3}$, Adiabatic constant $=0.0 \mathrm{~kg} / \mathrm{m}^{3}$,

Reference temperature $=288.2 \mathrm{k}$, Specific heat $=717.3 \mathrm{~J} / \mathrm{kgk}$,

Reference energy $=2.068 \times 105 \mathrm{~mJ} / \mathrm{mg}$

\section{RESULTS AND DISCUSSION}

The response of displacements and strains, for all models are determined at different lining points.

\section{Displacements}

The relation between peak displacement responses and lining thickness-radii ratio for crowndetonation distance 10 and $15 \mathrm{~m}$ respectively is presented in figure (6) and figure (7). The peck response of tunnel crown is shown in figure (8). From these figures, the following observation can be noted: 

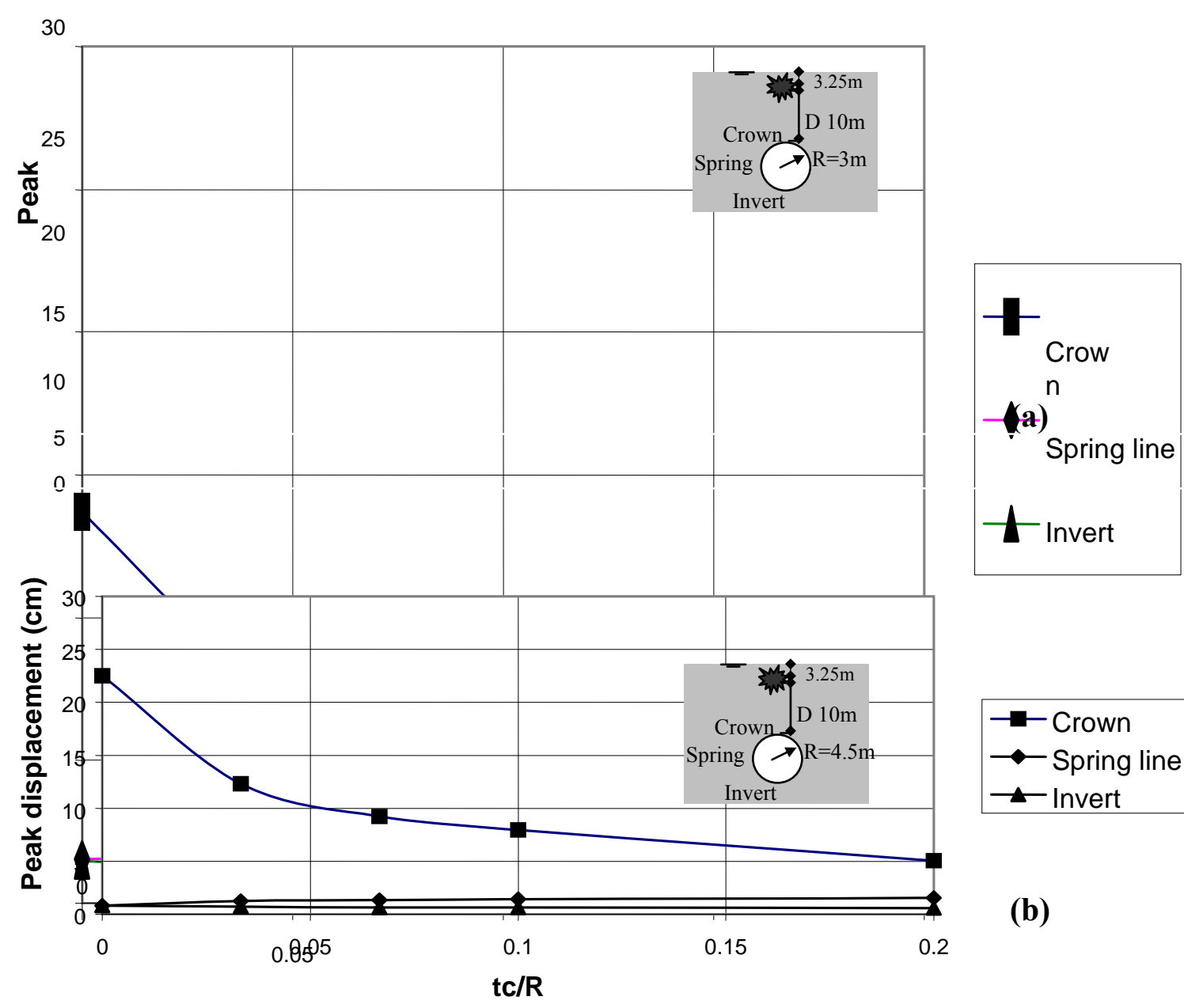

0.1

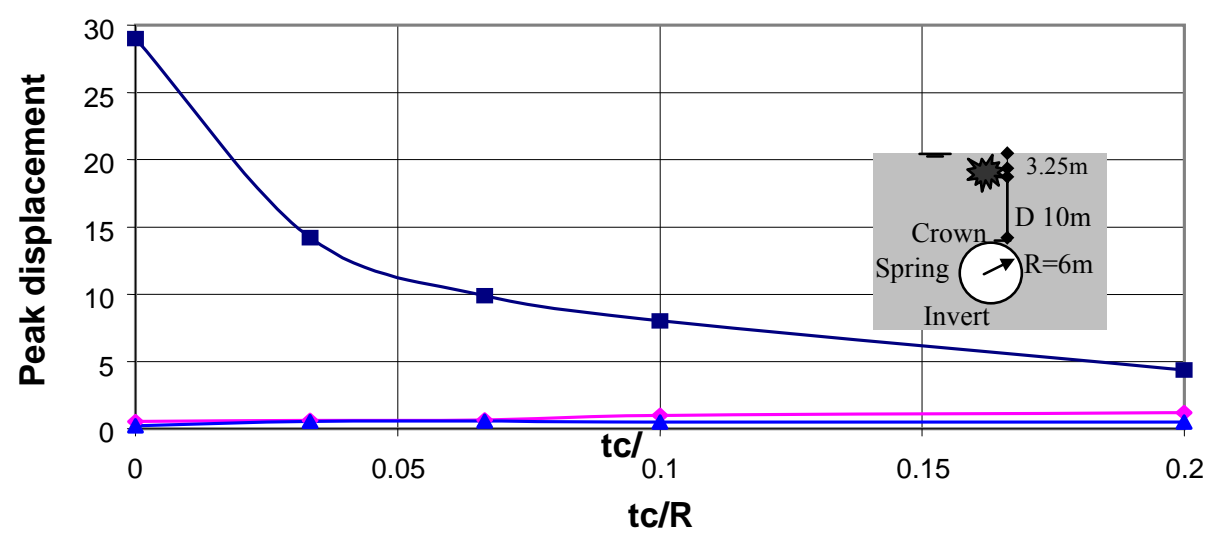

(c) 
Fig.6 Peak Displacements of Crown, Spring and Invert Points of Tunnel Versus the ( $\left.t_{c} \backslash R\right)$ Ratio for $10 \mathrm{~m}$ Crown-Detonation Distance
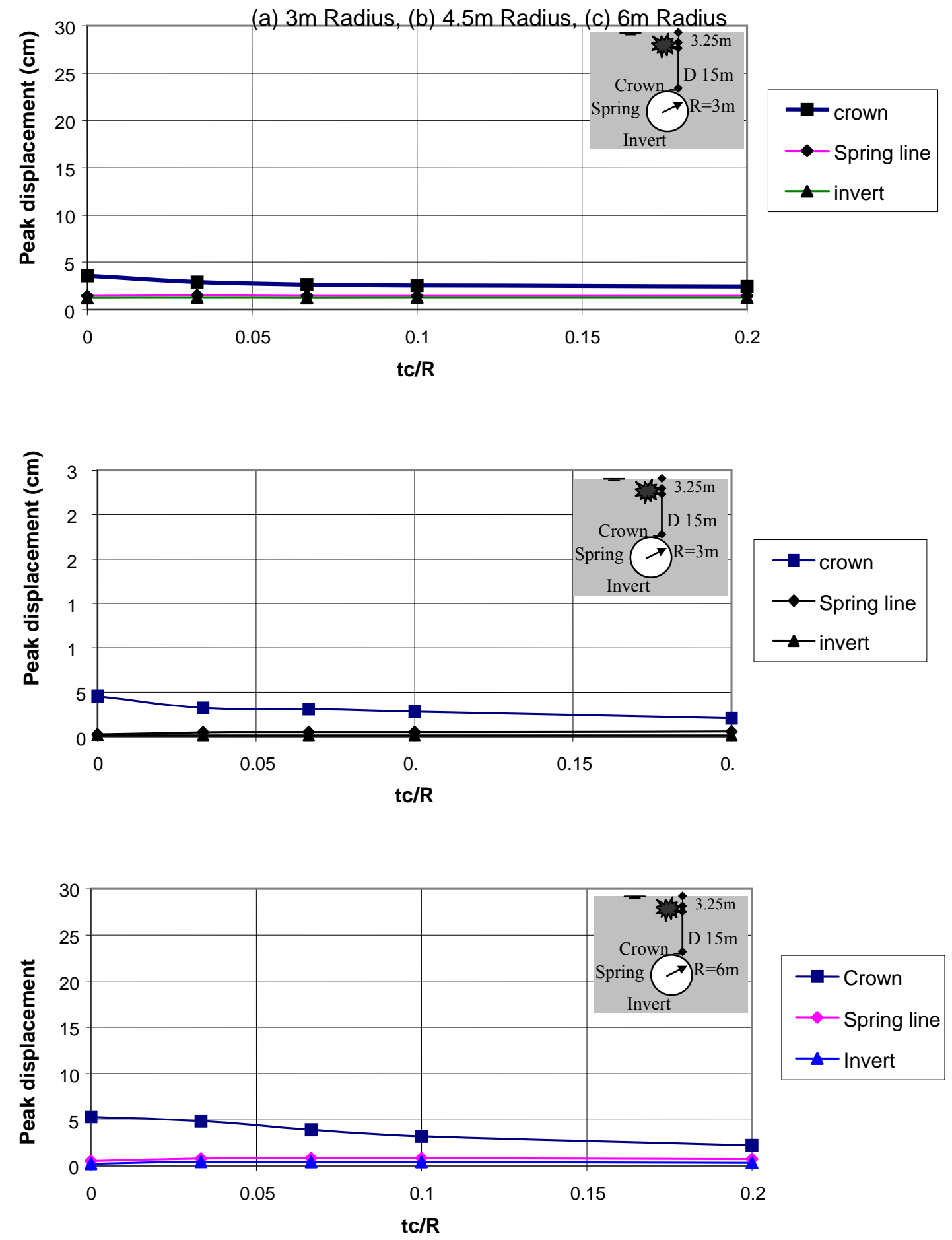

Fig.7 Peak Displacements of Crown, Spring line and Invert Points of Tunnel Versus the $\left(t_{c} \backslash R\right)$ Ratio for $1 \mathrm{~m}$ Crown-Detonation Distance

(a) $3 m$ Radius, (b) $4.5 m$ Radius, (c) $6 m$ Radius 


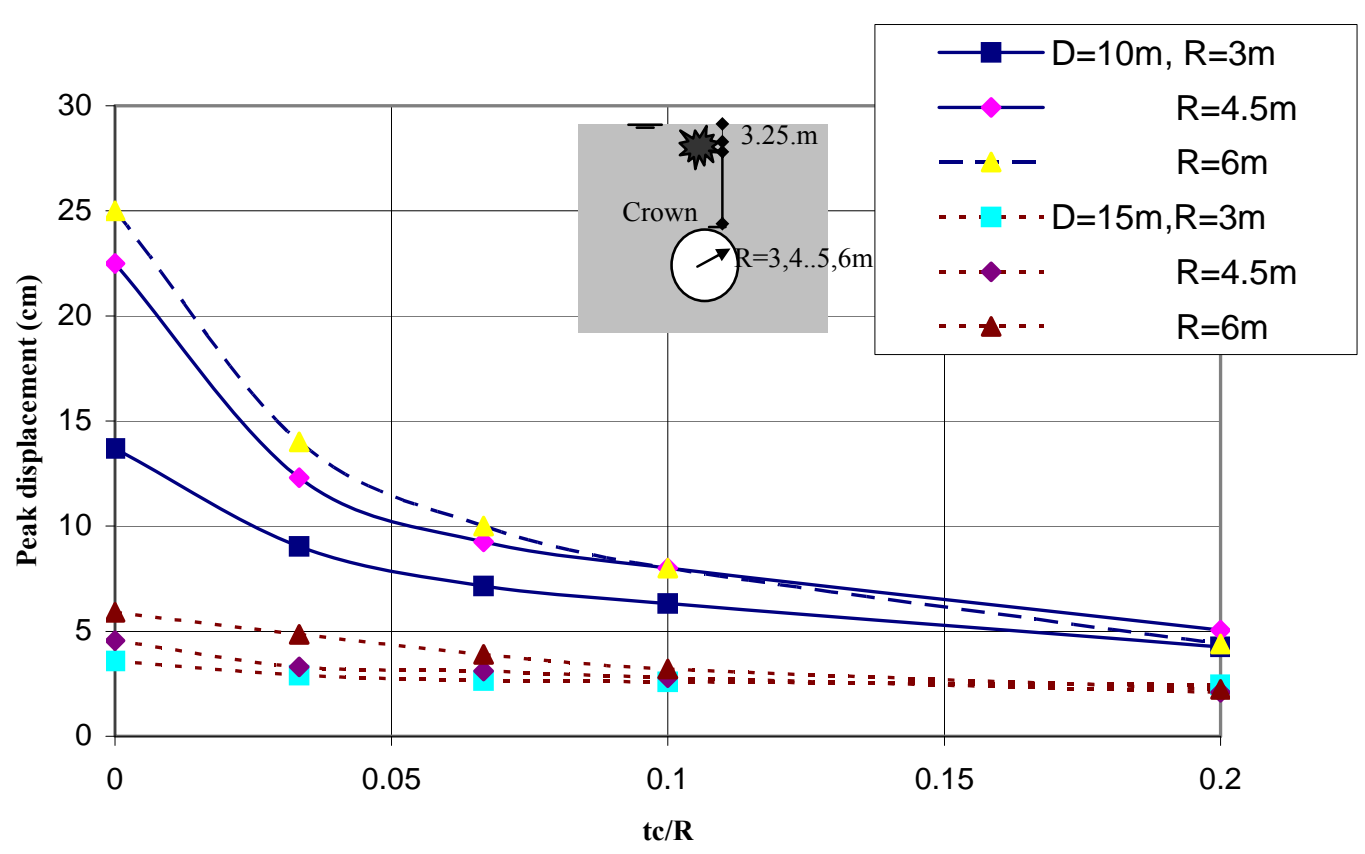

Fig.8 Peak Displacements of Crown Point of Circular Tunnel Versus (tc $\mathrm{R}$ ) Ratio for Different Radii and Crown-Detonation Distances 10 and15m.

1. For Crown-Detonation Distance 10m:

a) The displacements are maximum at the crown point. The increase in tunnel thickness $\left(\mathrm{t}_{\mathrm{c}}\right)$, causes a decline in vertical displacement. This decline is much more noticed up to $\left(t_{c} / R\right)=0.05$.

b) The effect of lining thickness on the peak vertical displacement at spring line and invert are insignificant and can be neglected.

c) The tunnel with radius $6 \mathrm{~m}$ experienced displacement values more than radius $4.5 \mathrm{~m}$ case and radius $3 \mathrm{~m}$ case by $136 \%$ and $175 \%$ respectively when the lining thickness ratio (tc/R) less than 0.1 , while the peak displacement of the three tunnel radii become nearly the same when the lining thickness $\left(t_{c} / R\right)$ became 0.1 and there is no effect of tunnel radius.

\section{For Crown-Detonation Distance 15m:}

a) The displacements are maximum at the crown point.

b) The effect of lining thickness on the peak vertical displacement at spring and invert are insignificant and can be neglected especially when the tunnel radius is greater than $4.5 \mathrm{~m}$.

c) The maximum radius $6 \mathrm{~m}$ experienced displacement values more than radius $4.5 \mathrm{~m}$ case and radius $3 \mathrm{~m}$ case by $127 \%$ and $164 \%$ respectively when the lining thickness ratio (tc/R) less than 0.075 , while the peak displacement of the three tunnel radii become nearly the same when the lining thickness (tc/R) became 0.075 then there is no effect of tunnel radius on the peak displacement. 


\section{Plastic Strain}

The plastic strain of concrete lining tunnel for different lining thickness and two crown-detonation distances $10,15 \mathrm{~m}$ is shown in figure (9) and figure (10).

From these figures, the following remarks can be concluded:

\section{For Crown-Detonation Distance10m}

a) The plastic strain decreases when the lining thickness increases.

b) The plastic strain decreases when the tunnel radius increases.

c) The plastic strain exceeds failure strain at different thickness lining when $D=10 \mathrm{~m}$, consequently the concrete reaches full damage at tunnel crown. The concrete lining is not considered convenient because it requires large thickness.

\section{For Crown-Detonation Distance 15m:}

a) The maximum of plastic strain to failure strain equal to $35 \%$ consequently, for all cases the plastic strain dose not reach failure strain.

b) The maximum effective radius on the plastic strain dose not exceeds $20 \%$.

c) The plastic strain dose not exceed failure strain at different thicknesses lining, consequently, the concrete dose not reach full damage at tunnel crown. The concrete lining may be considered convenient as tunnel lining.

\section{RATIONAL ANALYSIS}

The parametric study results were statistically treated to develop simple equations to determine peak displacements and strains at the tunnel crown. The commercial software DataFit [2] is used to determine the best-fit parameters for a model by minimizing a chosen merit function.

The predicted equations of peak displacement and plastic strain at tunnel crown are shown in the following equations:

$$
\begin{aligned}
& \delta_{\text {crown }}=17.284 . e^{\frac{30}{D}} \cdot \frac{R^{0.8}}{D} \cdot \frac{1}{(0.3 E+0.8936)^{1.4}} \cdot\left(\frac{1}{1+0.186 . t_{c}^{0.559}}\right) \\
& \varepsilon_{\text {crown }}=27.33 \cdot \frac{1}{e^{0.5717 D+0.06316 R+0.01852 t_{c}}}
\end{aligned}
$$

Where:

$\boldsymbol{\delta}_{\text {crown }}$ : Peak displacement at tunnel crown (cm)

E : Modulus of elasticity of rock (Gpa)

$\boldsymbol{\varepsilon}_{\text {crown }}$ : Peak strain at tunnel crown

D : Crown-detonation distance $(\mathrm{m})$

$\mathbf{t}_{\mathbf{c}} \quad$ : Concrete lining thickness $(\mathrm{cm})$

$\mathbf{R} \quad$ :The tunnel radius $(\mathrm{m})$ 

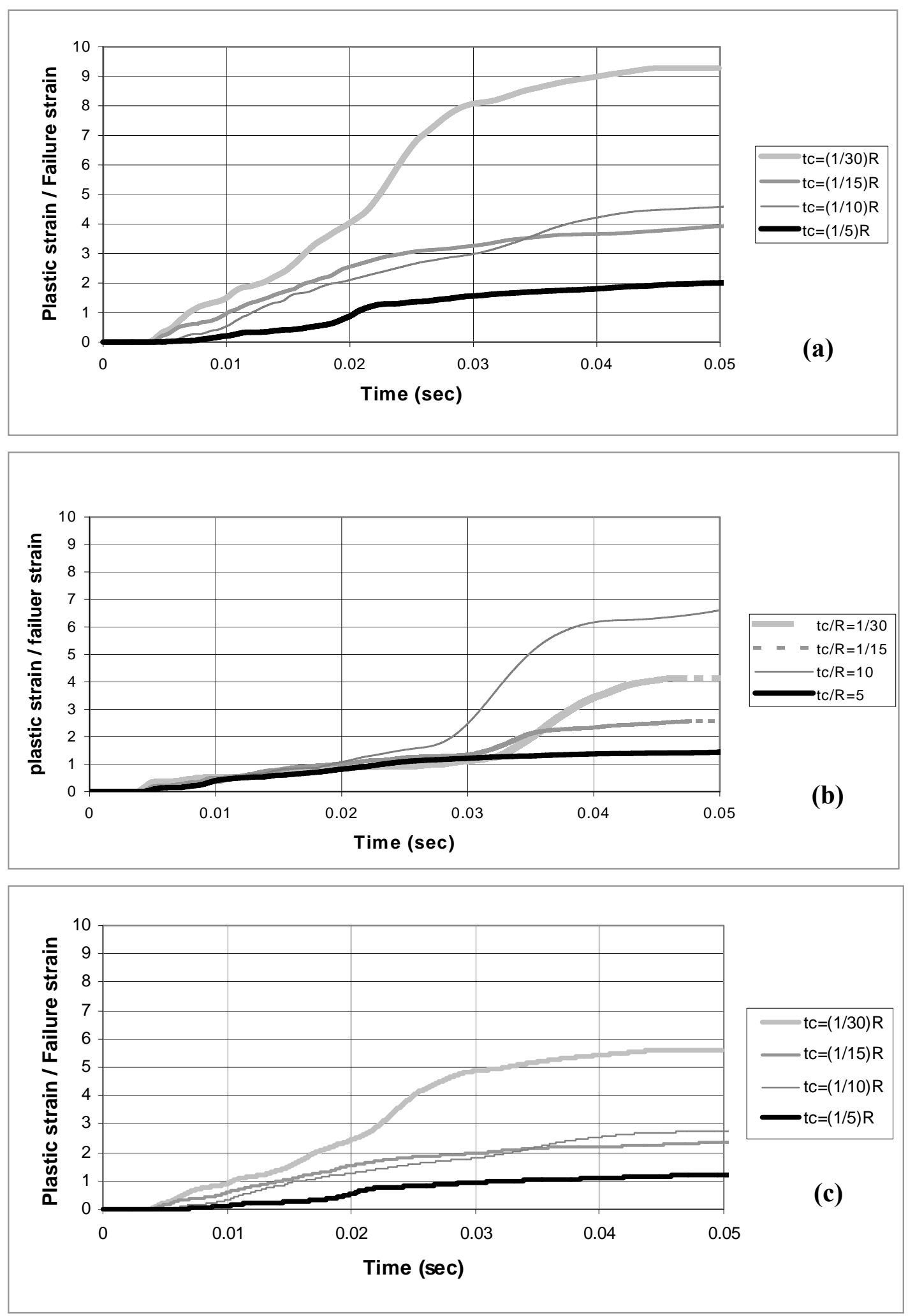

Fig.9 Plastic Strains Time History of Crown Point for $10 \mathrm{~m}$ crown-Detonation Distance (a) $3 m$ Radius, (b) $4.5 m$ Radius, (c) $6 m$ Radius 

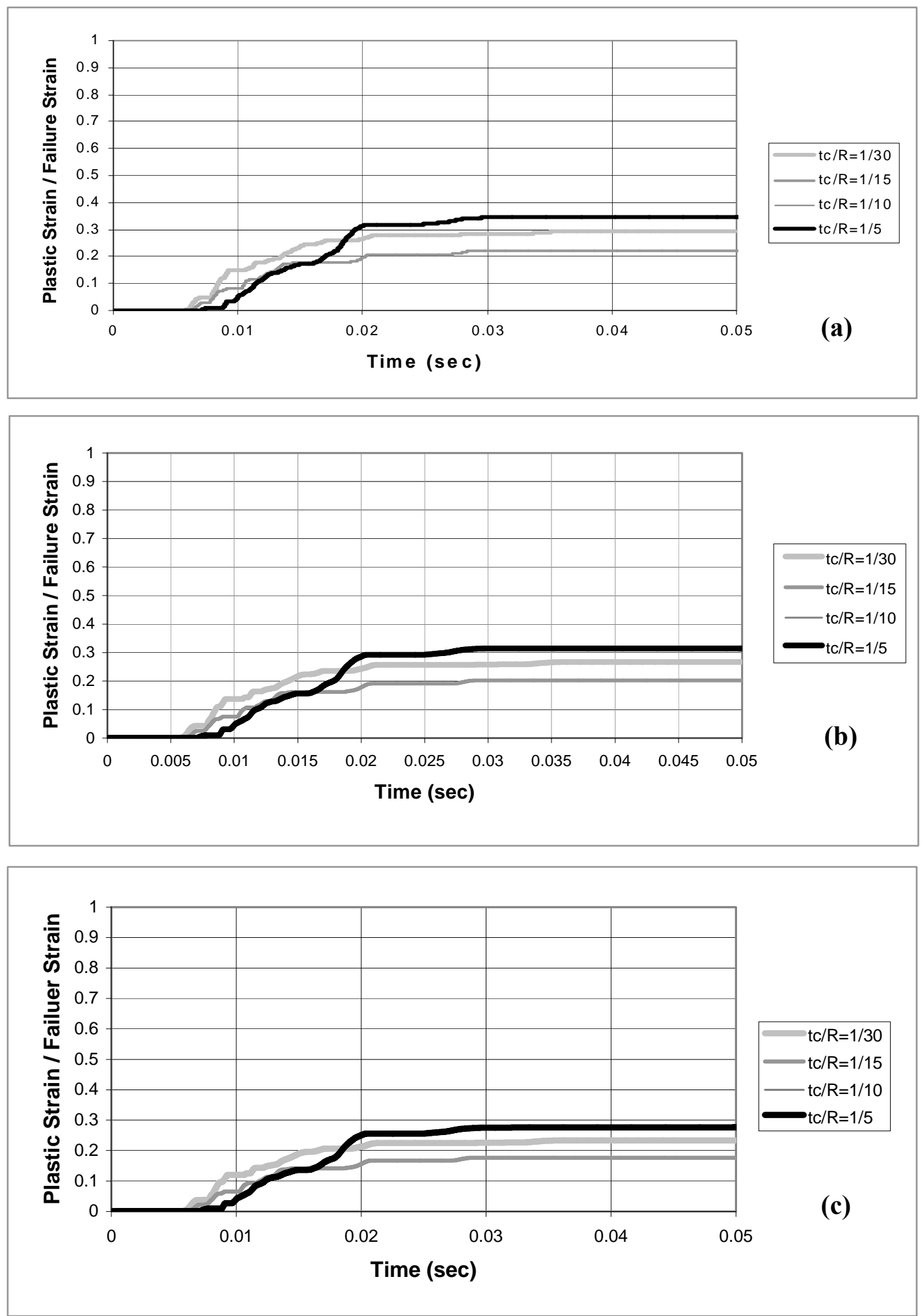

Fig.10 Plastic Strains Time History of Crown Point for $15 \mathrm{~m}$ crown-Detonation Distance (a) 3m Radius, (b) 4.5m Radius, (c) $6 \mathrm{~m}$ Radius 
Figures 11 and 12 present a comparison between FE and predicted equation results of peak displacements at tunnel crown for different tunnel radius for $10 \mathrm{~m}$ and $15 \mathrm{~m}$ crown-detonation distances respectively. From these figures we can notice that the results predicted by the equations are too close with those of finite element with error about $11.3 \%$ and $1 \mathrm{~cm}$ standard error for displacement, and about 19\% error and 0.006 standard error for the strain. In most tunnel cases these equations are valid but with practical range limitations. These limitations in range are, from $10 \mathrm{~m}$ to $20 \mathrm{~m}$ for crown detonation distance, from 3 to $6 \mathrm{~m}$ for tunnel radius, and rock modulus of elasticity, which is derived from the Rock Mass Rating (RMR), should be ranged from 8.5GPa to 70GPa.

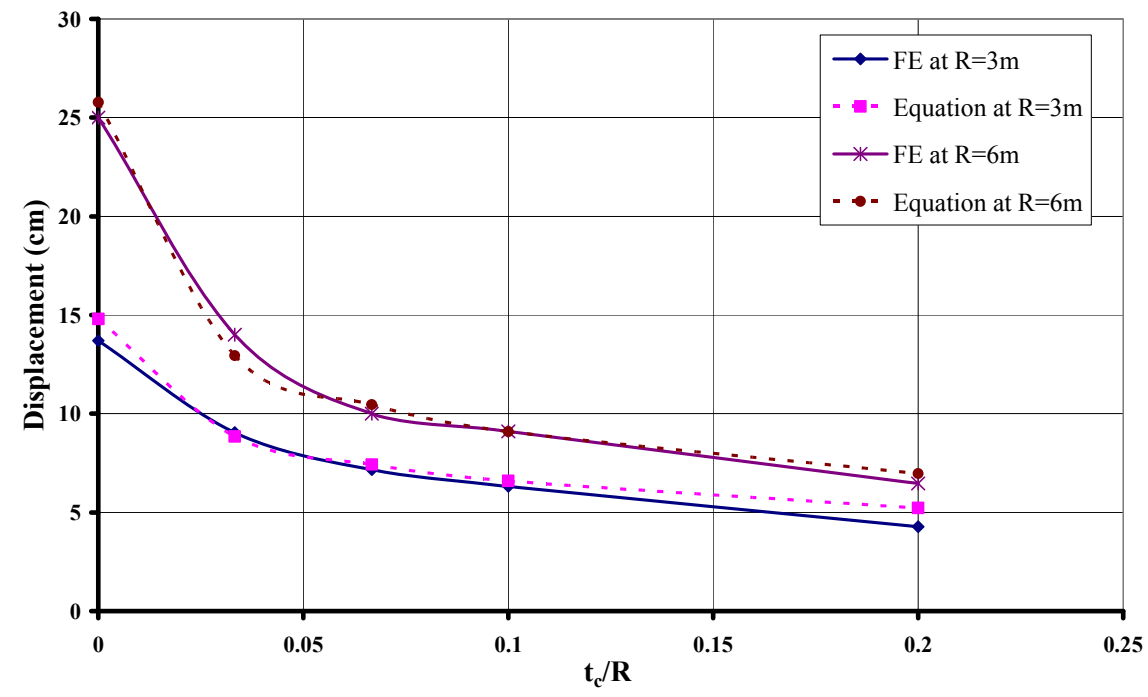

Fig.11 Comparison Between FE and Predicted Equation Results of Peak Displacements at

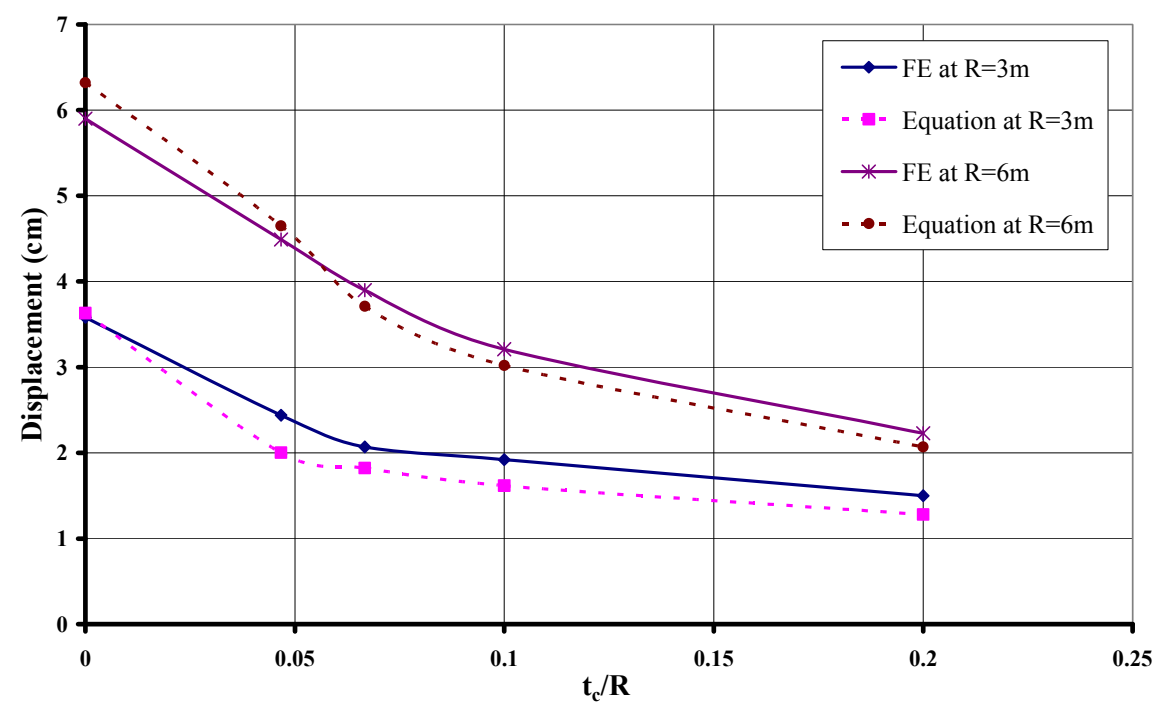

Fig.12 Comparison Between FE and Predicted Equation Results of Peak Displacements at 


\section{CONCLOUSION}

It is convenient to use the concrete lining for tunnels constructed through poor rock. The peak displacement at tunnel crown decreases when the (tc/R) ratio increases. The economic ratio of concrete lining thickness (tc/R) is 0.1 for both crown-detonation distances 10 and $15 \mathrm{~m}$. this thickness gives reasonable peak displacements at tunnel crown. The peak displacements values at spring and invert are not dependent on the (tc/R) ratio.

The estimating values of displacements and strains computed by predicted simple equations obtained by the nonlinear regression analysis showed a good agreement with the results of the complicated finite element models.

\section{REFERENCES}

1) AUTODYN, Computer Finite Element Program, 2003.

2) DataFit, computer statistical program, 2005.

3) Fred G. B. , "Engineering Properties of Soil and Rock", Department of Geology and Applied Geology, University of Natal, Durbon, South Africa, Blackwell Science, 2000.

4) Husin A. Lolo, and Ismail M. et al, "Parametric Study for Circular Tunnels without Lining Subjected to Underground Explosion in Rock Media", Ain Shams University, $11^{\text {th }}$ International Colloquium on Structural and Geotechnical Engineering, 2005.

5) Lee F., and Collins "JWL Equation of State Coefficients For High Explosives" UCID-16189, January 1973.

6) Riedel W., "Impact and Explosion RHT. Model", PhD Thesis, EMI report no. 6/00, Freiburg, Germany, July, 2000.

7) Riedel W.,Thoma K., Hiermaier S. and Schmolinke, E., "Penetration of Reinforced Concrete by Beta-B-5000 Numerical Analysis Using a New Macroscopic Concrete Model for Hydrocodes", Proceedings of the 9th International Symposium on the Effects of Munitions with Structures, Berlin-Straussberg, Germany, 1999.

8) Wiliams o., "Engineering Design of Tunnels and Shafts in Rock”, CECW-ED, Department the USA Army Corps of Engineers, 1997.

9) Zhou Y., "Numerical Analysis of Blast-Included Stress Wave in Anisotropic Rock Mass With Continuum Damage Model", Defense Science and Technology Agency, USA Ministry of Defense, 2001. 